\title{
EDITORIAL
}

\section{TÊNUES FIOS DE INTERAÇÃO ENTRE EDUCAÇÃO \& LINGUAGEM}

Os termos Linguagem e Educação nos representam um campo de estudos e um setor da realidade concreta que, mais do que qualquer outro, abarca e inclui o objeto primordial de qualquer ciência humana:

o homem. Como tal, este é um sujeito que vive, pensa, age, fala e conhece, num mundo concreto e numa complexidade de interrelações, de modo que a produção de conhecimentos, no processo e no produto, acerca desse objeto deverá estar em conformidade com a própria realidade investigada, considerando toda a sua complexidade.

[...] linguagem e educação são fatos de uma mesma natureza, como também o são todos os demais fatos na ordem da cultura e mantêm todos entre si alguma relação por mais distante ou mais próxima que seja. A proximidade entre linguagem e educação parece muito óbvia. [...] tentaremos situar a noção de linguagem no contexto educacional na medida em que se constitui indubitavelmente um componente necessário, básico mesmo, de toda e qualquer relação pedagógica que possa ser caracterizada como de ensino-aprendizagem.

(COSTA, 1996, p. 40-42)

É de interação que a autora nos fala, criando pontes de intersecção/aproximação entre linguagem e educação, atribuindo a esta, a possibilidade de ser mediada pela primeira. Linguagem e educação, constituem assim, pontos-chaves para a legitimação do processo interacional, como também nos diz Berticelli (2004, p. 83-84): "[...] não se oferece outro caminho senão o da linguagem, único acesso ao ser da educação [...]. A educação é linguagem. [...] $\mathrm{Na}$ palavra, a educação se diz. Na linguagem como lugar aparece o acontecer da educação e em nenhum outro lugar", sendo assim, inseparáveis.

É, portanto, desse 'lugar' que enunciamos, ao, neste dossiê temático, intitulado: Educação \& linguagem: das faces constitutivas e interativas, reunirmos resultados de pesquisas teóricas e aplicadas de pesquisadores da área de Educação (Pedagogia) e Linguagem (Linguística), profissionais que têm em comum, a preocupação com um ensino interativo e indissociável das práticas sociais.

Ciente desse recorte, com satisfação, aceitei o convite para organizar a presente edição (vol. 4, no. 1, 2019) da Revista Cadernos Cajuína, que ora apresento. O periódico, que teve seu primeiro número publicado em julho de 2016, 
com uma abordagem interdisciplinar, vem agora, desde edições recentes (a primeira foi o vol. 3, n‥ 2, 2018), organizando-se em forma de dossiês temáticos, fato que revela maior preocupação com a consolidação de estudos científicos sobre áreas do conhecimento mais específicas. Fato que considero positivo e, portanto, nos enche de orgulho, por presenciar a legitimação acadêmica de pesquisas que são valorosas, pela profundidade e consistência nas discussões, comprometidas com o caráter crítico e reflexivo.

Neste número, a autoria dos textos é atribuída a especialistas em suas áreas de formação, e que buscam construir interfaces (inter) ativas entre educação e linguagem. Isso porque, compartilhamos do entendimento de que a linguagem é um fio condutor da educação, e de que ambas, constituem práticas sociais humanizadas e humanizadoras, capazes de promover a transformação social e aproximar os sujeitos, que, pela via da criticidade, da reflexividade e da tomada de consciência, constroem um protagonismo social ativo. E como nos alimenta o pensamento de Paulo Freire (2000, p. 67), nosso cidadão brasileiro, nordestino, considerado o maior educador do século $X X$, e quem nos saúda com a bela imagem da capa deste dossiê: "Se a educação sozinha, não transforma a sociedade, sem ela tampouco a sociedade muda".

Assim, com o enfoque mais voltado para a Educação, abrimos esta edição, com o primeiro artigo: Narrativas (auto) biográficas, memória e docência, escrito por Sebastião Silva Soares. O autor desenvolve uma reflexão sobre as narrativas (auto) biográficas no âmbito da formação e do desenvolvimento profissional de professores, além da sua aplicação na pesquisa em educação, salientando a pertinência desse procedimento teórico-metodológico para compreender a experiência autoformativa e simbólica, narrada por interlocutores em ação.

Em Racionalidades pedagógicas que fundamentam a Licenciatura em Educação do Campo, o segundo artigo, escrito por Raimunda Alves Melo e Antonia Dalva França-Carvalho trata das diferentes racionalidades pedagógicas que orientam os processos formativos do curso de Licenciatura em Educação do Campo da Universidade Federal do Piauí, Campus de Teresina. As autoras salientam que as políticas de formação de professores carecem de um olhar crítico sobre as racionalidades que fundamentam seus processos formativos, objetivando entender suas relações com os diferentes interesses políticos, econômicos e sociais. 
No terceiro artigo: Educação de Jovens e Adultos e ferramentas tecnológicas: um diálogo sobre o contexto da inclusão digital, Jovina da Silva e Geraldo de Castro Gomes tratam sobre a necessidade de um diálogo de inclusão digital na Educação de Jovens e Adultos (EJA), por meio de ferramentas tecnológicas, visando enfrentar os desafios que o público-alvo dessa modalidade de ensino enfrenta no uso das tecnologias, de forma que contribua para uma educação menos excludente e que insira os sujeitos na sociedade na era da Informação.

Conhecendo os alunos com altas habilidades e superdotação como condição para uma efetiva inclusão escolar é o quarto artigo do dossiê, de autoria de Camila Dias Andrade Wenzel e Jacqueline Wanderley Marques Dantas. As autoras discutem sobre a educação inclusiva, de forma específica, do reconhecimento das necessidades dos alunos com Altas Habilidades/Superdotação (AH/SD) por parte dos professores, enfatizando a importância de sua capacitação para uma efetiva mudança no processo de escolarização no Brasil.

$O$ artigo A criança em processo de aprendizagem da Libras: nas sutilezas do ato de inclusão escolar, escrito por Maria Helena de Oliveira e Francisco Renato Lima é o quinto do dossiê. Os autores, por meio de um estudo de caso, acompanham a trajetória de uma criança deficiente auditiva, no processo de ensino e aprendizagem escolar, mediada pela Libras. Ressaltam, a importância do ensino de Libras nas escolas como primeira língua dos surdos, confirmando que, quanto mais cedo as crianças aprenderem, melhor será o seu desenvolvimento.

Douglas Pereira da Costa, no sexto artigo, intitulado: Gincanas como espaço de formação docente: das (inter)faces possíveis em um curso de Pedagogia, relata, de forma bem contextualizada teoricamente, uma experiência docente ao lecionar a disciplina de Gestão e Educação Ambiental a alunos de uma turma de Pedagogia. $O$ autor apresenta a gincana como uma metodologia ativa, que oportuniza ao aluno de nível superior, experiências de autogerenciamento, individualmente e em conjunto, de forma crítica e criativa.

O sétimo artigo, intitula-se Socialização da disciplina Tópicos Especiais em Educação: um breve estudo sobre categorias numa perspectiva sóciohistórica, escrito por Smael Maicon de Sousa Lima e Carmen Lúcia de Oliveira Cabral. Nele, os autores discutem sobre a Psicologia Sócio-histórica de Vygotsky, com foco nas categorias: Atividade, Consciência, Significado e Sentido, Pensamento 
e Linguagem, e, em como elas, podem ser articuladas às pesquisas científicas em Educação, especialmente no campo da formação de professores.

Já, com o enfoque mais voltado para a Linguagem (Linguística), a edição segue com o oitavo artigo, denominado: Estudos sobre alfabetização e letramento no Brasil: gêneses, desenvolvimentos e aplicações no ensino, escrito por Francisco Renato Lima. O texto traz um apanhado teórico sobre os processos de alfabetização e letramento no Brasil, destacando aspectos de suas gêneses, desenvolvimentos e aplicações no ensino, com foco em permanências e mudanças paradigmáticas em suas práticas, advindas, principalmente, da influência da psicogênese da aquisição da língua escrita - o construtivismo, e também, das pesquisas que tratam de letramento como prática social, as quais deram novos rumos às concepções teórico-práticas sobre o ensino da leitura e da escrita.

Práticas sociais de leitura e escrita de alunos na Educação de Jovens e Adultos e suas implicações no universo da cultura letrada é o nono artigo, de autoria atribuída a Aliny Cardoso dos Santos. Nele, a autora analisa como atividades propostas em sala de aula de uma turma de $8^{\circ}$ ano da Educação de Jovens e Adultos (EJA) relacionam-se ao universo dos alunos fora da escola. Constata que, mesmo estando inseridos numa cultura letrada, esses alunos ainda vivem à margem dela porque essa participação não é efetiva, uma vez que, não há a participação plena, enquanto cidadãos em todos os setores artísticos e culturais.

Em Projetos de letramento na escola: de sua relevância como ponto de partida e de chegada da leitura e da escrita no mundo digital e no mundo do trabalho, o décimo artigo do dossiê, Antonio Artur Silva Cantuário aponta para a importância de desenvolver projetos de letramento na escola em turmas de EJA, envolvendo eventos e práticas de letramentos constantes na relação entre mundo profissional e mundo digital, interligados por meio das práticas de linguagem para atingir uma finalidade real: inserir-se no mercado de trabalho, o que pressupõe a aprendizagem de novos gêneros, promovendo a consciência crítica.

O décimo primeiro artigo, intitulado: $O$ ensino do pleonasmo na escola básica: por uma abordagem reflexiva e interacionista no tratamento da figura de linguagem e do vício de linguagem em aulas de Língua Portuguesa, foi escrito por Emanuelly Nascimento Gomes, lanara Wanderley Dias Leite dos Santos e Francisco Renato Lima. Os autores apresentam uma reflexão acerca do ensino do pleonasmo na escola básica, contemplando as relações entre os conceitos de figura 
de linguagem e vício de linguagem e como eles podem convergir em alguns aspectos, ilustrando situações em que o pleonasmo aparece como vicioso, um desvio da norma culta; ou como literário, uma expressão artística da linguagem.

Marcas linguísticas nordestinas presentes na obra Morte e Vida Severina, de João Cabral de Melo Neto: análise das designações é o décimo segundo artigo do dossiê. Escrito por Daniel dos Santos Teixeira e Safira Ravenne da Cunha Rêgo, o texto, construído sobre as bases teóricas da Sociolinguística Variacionista, analisa as designações textuais, que mostram como o fenômeno da variação por região, explica e caracteriza o sujeito nordestino apresentado na obra analisada, a qual, traz a representação da vida difícil e a resistência do retirante, diante de todos os desafios que enfrenta em suas lutas diárias.

Escrito por Nathalie de Jesus Maria Ribeiro e Safira Ravenne da Cunha Rêgo, o décimo terceiro artigo, intitulado O "silenciamento" da voz negra feminina: uma análise discursiva da obra de Maria Firmina dos Reis, trata, a partir da análise de três obras da autora maranhense, como o sujeito mulher negra sempre fora evidenciada por escritores brancos, de forma estereotipada dentro da literatura, fato que permitiu a construção de uma identidade inferiorizada, cristalizada no imaginário nacional, contribuindo assim, para a pouca representatividade de escritoras negras na literatura nacional, bem como no meio histórico e na mídia.

$\mathrm{Na}$ sequência, o décimo quarto artigo: Análise da ideologia evangélica conservadora do pastor Silas Malafaia em relação à abordagens sobre ideologia de gênero pela Disney em seus desenhos, escrito por João Borges da Silva e Juscelino Francisco do Nascimento, analisa o embate ideológico entre a classe liberal, representada pela atitude da Disney ao realizar abordagens em seus desenhos sobre a tematização da ideologia de gêneros e questões homoafetivas em geral; e a classe conservadora, representada pela análise do discurso do pastor Silas Malafaia, em questões que tangem a ideologia de gênero.

Tempo de resistência: o discurso de protesto na poesia de Chico Buarque é o décimo quinto artigo do dossiê. Escrito por Luiz Benigno dos Santos Filho e Vanessa Raquel Soares Borges, o texto examina o tipo de mensagem contida em três músicas do cantor e compositor Chico Buarque, tidas como "canções de protesto" no período do regime militar. Entre "cortes nas canções" e "respostas dadas", a poética musicada de Chico torna-se uma das mais relevantes 
da cultura brasileira, pois, mesmo ameaçado pelo Regime Militar brasileiro, emana discursos de enfrentamento através da Arte: a música.

\section{A patemização como recurso de persuasão em reportagem publicada} na Folha de São Paulo referente à professora Heley, escrito por Francisco Herbert da Silva, Demócrito de Oliveira Lins e João Benvindo de Moura é o décimo sexto artigo do dossiê e tem como propósito analisar a presença do efeito patêmico atrelado aos sujeitos da linguagem numa matéria publicada na Folha de São Paulo, que tem como referente, a Heley, professora que tentou impedir o incêndio na creche de Janaúba (MG). Concluem que, os sujeitos da linguagem, naturalmente fazem uso de recursos argumentativos e persuasivos, como por exemplo, o pathos, objetivando influenciar e promover à adesão dos interlocutores a tese.

Em Os atos de fala em Maitena: Superadas, o décimo sétimo artigo do dossiê, foi escrito por Thiago de Sousa Amorim e Iveuta de Abreu Lopes. Os autores, partindo dos princípios da Pragmática e da Teoria dos Atos de Fala, analisam quatro exemplares do gênero textual quadrinho, como forma de testar a evidência das categorias de análise previstas: os atos locucionários, ilocucionários e perlocucionários. Concluem que esses postulados teóricos possibilitam um olhar mais apurado sobre o significado linguístico a ser interpretado por um contexto extralinguístico em dada sentença.

Finalizando a edição, temos a sessão Acervo literário, com dois poemas. $\mathrm{O}$ primeiro: Cheiro das terras de meu pai, de Francisco Renato Lima; e Desejo de liberdade, escrito por Elara Araújo Moretz-Sohn.

Destacamos que, diante dessa diversidade de temas e experiências de pesquisa, os autores mencionados assumem a inteira responsabilidade sobre 0 conteúdo de seus textos, de maneira que, encontram-se inclusive disponíveis para contatos e questionamentos, via e-mail, conforme disponibilizado nos artigos.

Por fim, juntamos nossas vozes, acreditando que, com a publicação deste número e o empenho com a qualidade dos trabalhos, a Revista Cadernos Cajuína, de alguma maneira, tem contribuído com a ampliação do conhecimento na área de Educação e Linguagem, campos de conhecimento convergentes e entrelaçáveis, aqui materializados por meio de palavras (enunciados), 'tecido ideológico', que segundo Bajtín (1975, p. 89-90), 
[...] encontra o objeto que é dirigido ao falado [...], discutindo, avaliando, envolto em uma neblina que Ihe faz sombra ou, ao contrário, na luz das palavras alheias já ditas sobre ele. Encontra-se enredado e penetrado por ideias comuns, ponto de vista, avaliações alheias, acentos. A palavra orientada ao seu objeto entra neste meio dialogicamente agitado e tenso das palavras, valorações e acentos alheios, se entrelaça com suas complexas interrelações, funde-se com umas, repele outras, entrecruza-se com terceiras.

Você leitor, a quem nos 'dirigimos', esperamos boa acolhida na leitura!!!

Prof. Me. Francisco Renato Lima ${ }^{1}$

Editor/organizador deste dossiê temático V. 4, N. 1, 2019 - Revista Cadernos Cajuína

\section{REFERÊNCIAS}

BAJTÍN, M. M. Problemas literarios y estéticos [en ruso]. Moscú: Judozhestvenaia Literatura, 1975. (Tradução: BAKHTIN, Mikhail. Questões de Estética e de Literatura: a teoria do romance. Tradução Aurora F. Bernardini et al. 7. ed. São

Paulo: Hucitec, 2014.)

BERTICELLI, Ireno Antônio. A origem normativa da prática educacional na linguagem. Injuí: Unijuí, 2004.

COSTA, Catarina de Sena Sirqueira Mendes da. Linguagem: uma noção.

Linguagens, Educação \& Sociedade: Revista do Mestrado em Educação da UFPI. Teresina, vol. 1, № 1, pp. 39-45, 1996.

FREIRE, Paulo. Carta-Prefácio. In: FREIRE, Paulo. Pedagogia da indignação: cartas peda-gógicas e outros escritos. Apresentação de Ana Maria Araújo Freire. São Paulo: Editora UNESP, 2000.

\footnotetext{
${ }^{1}$ Graduado em Pedagogia (UNIFSA) e Letras - Português/Inglês (IESM). Mestre em Letras - Estudos da Linguagem (UFPI). Professor Substituto (Auxiliar Nível - I) da Universidade Federal do Piauí, lotado no Departamento de Métodos e Técnicas de Ensino (DMTE). Coordenador de disciplinas do Centro de Educação Aberta e a Distância (CEAD/UFPI). Email: fcorenatolima@hotmail.com
} 